\title{
A ALAVANCA DA CRISE: A POESIA "PÓS- UTÓPICA" DE HAROLDO DE CAMPOS
}

\author{
Marcos Siscar \\ (UNICAMP - CNPq)
}

«Deem-me um ponto de apoio e moverei a

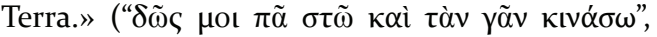
frase atribuída a Arquimedes por Pappus de Alexandria em Synagoga, Livro VIII).

Michel Deguy conta, em Réouverture après travaux, que havia pensado em intitular esse seu livro Manifesto pela poesia, a exemplo de um título de Alain Badiou. O poeta e crítico francês, entretanto, teria voltado atrás na decisão, por uma razão precisa:

Não intitulei este opúsculo "manifesto pela poesia", embora tivesse vontade de fazê-lo, encorajado pela emulação já proposta por Alain Badiou (com seu "manifesto pela filosofia"). Isso porque o tempo dos Manifestos se concluiu exatamente com Breton, que põe fim à era do Romantismo, apesar das réplicas sísmicas posteriores (na França, tivemos o manifesto frio, o elétrico, entre outros...). Eu certamente poderia dizer com Badiou que a idade dos poetas terminou, mas apenas se - aproveitando-me da permutabilidade dos três componentes da famosa tríade: poesia / poema / poeta - eu fingir acreditar que Badiou também está constatando o encerramento do Romantismo. Porém, como o leitor tem razão de conjecturar, se ele anuncia - de certo modo, acrescenta - a extinção da possibilidade de transformação da poesia (nos termos que colocarei), da literatura e de várias outras coisas conexas, por um exorcismo hiperbólico que pretende acabar com o juízo da poesia, nesse caso, eu preferiria escrever: começa a idade do parabólico ou da escrita num sentido 
profano aumentado, que é aquele do "poema" transformado, de mais um avatar de "fim do mundo" (Baudelaire) ou do "pensar-falar-escrever: o mesmo". (DEGUY, 2007, pp. 59-60)

O livro não se chama, portanto, Manifesto pela poesia porque a idade dos manifestos teria se esgotado juntamente com uma grande época chamada Romantismo. O pitoresco da decisão, enunciada dentro do próprio livro, é sensível no contexto do debate sobre a natureza do fim da poesia, interpretado por Badiou (mas não por Deguy) como uma extinção. Se não se trata de um manifesto, é porque alguma coisa distinta deve ser levada em conta: em específico, para Deguy, a metamorfose da poesia em outra coisa, ainda que presa na "sinonímia" do nome "poesia". Por meio dessa metamorfose, caminhamos na direção do que ele chama de idade do parabólico, uma curva que, ao levar em conta a ideia de um fundo, de fim da linha, relança o movimento. Nesse sentido, o poema seria um avatar do "fim do mundo". A decisão do autor tem a ver, portanto, com outra visão do fim, do que quer dizer o fim e de como um poema pode nomeá-lo.

Evidentemente, a retórica da negativa pela qual Deguy descarta a (falsa) solução do título é a mesma que insinua sua importância. O livro não se chama Manifesto pela poesia, mas poderia (ou deveria) ter esse nome, não fosse tudo aquilo que ele próprio descreve (o fim dos manifestos e da poesia como era entendida, a idade do cultural, da patrimonialização generalizada e da cultura turística). E, se não é um manifesto, não é porque o juízo da poesia acabou, mas porque se transformou.

Essa situação retórica me parece particularmente interessante na medida em que sugere outras formas de descrever a mesma questão. A julgar casos como esse, vivemos uma época para a qual o fim dos manifestos é um problema, ou passou a ser um problema. Se colocarmos entre parênteses a constatação histórica pura e simples de que a época dos manifestos se concluiu, teríamos que admitir que texto de Deguy é um manifesto (ou seja, algo que no passado chamaríamos um manifesto); um manifesto que tem sua própria retórica, suas estratégias específicas e que, detalhe importante, não pode mais ser assumido como tal. Em outras palavras, o que a argumentação de Michel Deguy me sugere é que talvez continuemos a escrever manifestos, mas de outra forma. O livro em questão é um exemplo disso. Trata-se de um diagnóstico amplo e argumentado da situação contemporânea da poesia e das artes, no qual o tônus de defesa

${ }^{1}$ O livro foi publicado no Brasil, em 2010, pela Editora da Unicamp. 
da "razão poética" está, por assim dizer, claramente manifesto e só pode ser comparado com a intensidade explícita do descontentamento que acompanha suas provas.

Outro caso a que gostaria de me referir é o de um ensaio de Haroldo de Campos - justamente, outro texto empenhado em estabelecer o fim da idade dos manifestos. Trata-se de "Poesia e Modernidade", de 1984 (CAMPOS, 1997). Em resumo, o ensaio faz o levantamento das oposições teóricas associadas à militância crítica que o poeta teve durante a época do concretismo, numa tentativa de suavizar seu caráter opositivo e proceder a uma espécie de dialética histórica que resulta na proposição do conceito de "pós-utópico" para designar aquilo que sucede à época das vanguardas, ou seja, a época da "pluralização das poéticas possíveis". Não me detenho aqui nos procedimentos complexos que sustentam essa argumentação. Remeto apenas ao fato de que, a propósito de constatar o encerramento das vanguardas e da época dos manifestos, Haroldo não deixa de escrever uma espécie de manifesto, mais enviesado, mas não menos efetivo que o de Deguy.

O tom moralizante das advertências no final do ensaio (a poesia não deve ensejar uma "poética da abdicação", tornar-se "álibi do ecletismo regressivo" etc.) é indício de um desejo de indicar linhas mestras, ainda que o texto seja, mais explicitamente, mais programaticamente, uma descrição histórica do contemporâneo como "época". Porém, o mais revelador talvez seja a recepção do ensaio, que ajudou a estabelecer - a exemplo do que faziam os manifestos - referências importantes sobre o contemporâneo, inclusive graças a sua força de interpretação histórica. Por essas razões, o texto é um acontecimento relevante para se pensar a situação recente da poesia, bem mais do que por aquilo que simula ou pretende constatar. Sua relevância instaura-se, antes disso, a partir de suas estratégias e de seu funcionamento, que eu chamaria de legislador (ou performativo).

Um indício revelador da performatividade do ensaio (que, por assim dizer, realiza o pós-utópico, no momento em que parece apenas fazer-lhe o diagnóstico) é a contracapa do livro de poemas $A$ educação dos cinco sentidos (1985), do próprio Haroldo de Campos:

Neste seu livro, Haroldo de Campos nos apresenta o momento pós-utópico de seu trabalho poético, que veio tomando corpo ao longo desses últimos anos, mas que já se insinuava, aqui e ali, em alguns poemas esparsos dos anos 60 e 70 . Poesia da agoridade, da construção do presente através da expropriação (e da reapropriação) crítica da tradição. (Grifos do autor). 
O livro de poemas, publicado pouco depois, é praticamente contemporâneo de "Poesia e Modernidade". As palavras grifadas na sua contracapa ("pós-utópico" e "agoridade") são também os dois termoschave do ensaio, vinculando diretamente o livro de poemas à proposta crítica recém-divulgada. Ou seja, o poeta constata o pós-utópico na produção crítica e, praticamente ao mesmo tempo, apresenta seu livro de poemas como pós-utópico. Naturalmente, a contracapa de um livro não é assinada; ela faz parte do trabalho editorial, ainda que normalmente com a anuência do autor. De todo modo, dificilmente seria possível dissociá-la de uma estratégia mais ampla que declara a época de pós-vanguarda para poder mais efetivamente assumi-la como projeto.

Textos como esse, que constatam o fim de uma época (no caso, mais especificamente, a morte da vanguarda), a meu ver, são manifestos em potencial - quem sabe os manifestos da "nossa época". Historicamente, para usar os termos da teoria dos "atos de fala", funcionam tanto como constativos quanto como performativos, por um tipo de contradição muito curiosa que permite ao texto encerrar alguma coisa que ele próprio inaugura, de outra maneira. Muito mais do que virar a página da época das vanguardas, por meio de seu suposto apagamento, o papel que têm é o de deslocá-la, reatualizando seus instrumentos e suas possibilidades.

Textos desse tipo não deixam de ter uma relação com o dispositivo da vanguarda, quando insinuam sua insatisfação com o que acontece, quando sugerem (ainda que de forma mediada, cautelosa, corretiva) que as coisas vão mal: é isso que motiva o projeto, o manifesto, a intervenção crítica ou criativa. Se o tom do ensaio é sereno, Haroldo não perde a oportunidade de marcar a distância que mantém em relação à paisagem sua contemporânea. Embora o pós-utópico seja seu tema, não cita nenhum nome, nenhuma formação discursiva pós-vanguardista, remetendo, no fundo - se pensarmos nos termos com que faz advertências aos contemporâneos a uma relativa frivolidade. Isso porque, a meu ver, o contemporâneo em questão não é, para Haroldo, apenas ou exatamente um campo de reflexão (aquele que o texto descreve e apresenta criticamente), mas é também, ou antes, um campo de ação. Diagnósticos semelhantes, como sabemos, foram confirmados posteriormente por críticos, como Heloísa Buarque de Holanda, que creditam vitalidade ao contemporâneo plural da poesia, ao mesmo tempo em que vêm a cercá-lo de restrições e convocações éticas e críticas, passando finalmente a uma diversificação de objetos e de contextos que se assemelha ao resultado de uma frustração ${ }^{2}$.

2 Penso, aqui, em específico, na "Introdução" ao livro Esses poetas: uma antologia dos anos 90 (HOLLANDA, 1998). 
São procedimentos que aproximam a prática da época dita pósutópica ao ethos da vanguarda. Em Haroldo de Campos, o ponto em que essa aproximação passa a ser visível, como experiência de reiteração quase maquínica, é a referência a Mallarmé como ponto de sutura do grande leque da tradição; ou, mais literalmente, no caso, como ponto de equilíbrio da alavanca com que o poeta pretende deslocar a leitura da tradição. Mallarmé (especificamente, seu poema mais radical, Um lance de dados) é, de acordo com a figura usada por Haroldo, um "ponto arquimédico", ou seja, um ponto de apoio. "Deem-me um ponto de apoio e moverei a Terra", teria afirmado Arquimedes. Embora o poeta tenha muitas vezes refutado a dimensão teórica e histórica da originariedade, de teleologia orgânica, não há como não ver aí uma espécie de arqué que cumpre a função do princípio, da fonte ou da causa. É difícil não encontrar em Mallarmé e na ousadia experimental do Lance de dados uma referência fundadora da obra e do pensamento de Haroldo de Campos, seu ponto de apoio um autor que coloca os termos a partir dos quais, desde o concretismo, Haroldo pensa e escreve poesia. Desde a dita "crise do verso", dentro da qual faria um "salto qualitativo" (segundo a Teoria da poesia concreta), Mallarmé tornou-se manancial de figuras fundamentais para a criação poética haroldiana, como a da constelação.

Uma evidência dessa transformação aparece no miolo do ensaio sobre a poesia pós-utópica. Para Haroldo, a relação com o poeta francês organiza toda a interpretação que se pode fazer da história da poesia no século XX. A lógica de vanguarda não é abandonada totalmente, pois Mallarmé continua sendo um "precursor": num primeiro momento (nos anos 1950 e 1960, digamos), era um precursor graças à percepção diferenciada da crise do verso; nos anos 1980, por supostamente já ter sido "pós-moderno", em relação a Baudelaire. Creio, entretanto, que o mais importante é assinalar como essa função de alavanca, por meio da qual o poeta-crítico entende movimentar a tradição, é aprofundada quando se faz de Mallarmé a medida historiográfica privilegiada das transformações da poesia no século XX.

Em "Poesia e modernidade", Mallarmé continua sendo o ponto em torno do qual gira toda a história da poesia moderna e contemporânea:

[...] toda uma história da poesia - uma "Pequena História (Radical) da Poesia Moderna e Contemporânea" - pode ser delineada, avaliando-se apenas as respostas que poetas de várias nacionalidades e línguas (e os latino-americanos entre eles) teriam dado ao poema-desafio de Mallarmé, à pergunta insinuada na breve introdução que o precede: "sans presumer de l'avenir qui sortira d'ici, rien ou presque un art”. (CAMPOS, 1997, p. 256) 
É claro que, em boa medida, a proposta visa legitimar o Concretismo, que é tratado como ponto decisivo dessa leitura. Mas é mais do que isso: além de aprofundar o âmbito no qual se dava essa importância, que vale agora para toda a poesia do século, a formulação passa a incorporar a própria historicidade da sua leitura: a história da poesia do século XX não é apenas a história da influência de Mallarmé, mas a história da leitura dessa obra à qual damos o nome de Mallarmé, isto é, das diferentes tentativas de dar sentido a esse corpus. Não se trata apenas de uma história da presença de Mallarmé neste ou naquele poeta, neste ou naquele grupo, mas de uma história de suas interpretações, da força com que essas interpretações nos interpelam, nos requisitam, ao se transformarem em obras. Esse passo, não o dá Haroldo explicitamente. Mas creio que define bem a configuração específica de seu "manifesto" pós-utópico.

Resumidamente, o ensaio dá à expressão "crise do verso" outra amplitude; ou melhor, vemos ali a tentativa de empreender uma passagem do Mallarmé da crise do verso para o Mallarmé da crise da arte, da poesia como um todo. Se Mallarmé é relevante, hoje, se é um precursor de nossa situação pós-utópica, não é porque é pós-moderno, no sentido do tratamento que dá à questão do destino das formas ou das estratégias de comunicação poética ${ }^{3}$, mas no sentido da visão que tem do moderno como um todo. E essa visão - que, em Haroldo, se tornará também uma sensibilidade quase profética - é a visão da crise.

Mallarmé é importante não por ter dado um tratamento hiperbólico à questão da comunicação, mas por ter captado parabolicamente (segundo o termo de Deguy) o "fim do mundo" da poesia. Se a identificação entre crise do verso e extinção da poesia é, comumente, uma sinonímia jornalística, trata-se, no caso de Haroldo, de usá-la como forma de redramatizar a leitura de Mallarmé, depois de esgotados seus esforços de vanguarda. Para Haroldo, Mallarmé tinha ou teve uma visão quase apocalíptica da crise. É dando relevo ao topos do fim do mundo da poesia que as estratégias do poeta brasileiro passam, então, a se associar à compreensão da poesia do século XX e de sua própria prática poética.

Retomo o texto de Haroldo nesse ponto. Fazendo uma longa citação de duas páginas de um texto de 1968, de sua própria autoria, "Poesia e modernidade" nos coloca diante da questão do jornalismo e dos novos

3 Mallarmé, autor de poemas formalmente inovadores (como Um lance de dados), tido como apreciador de jornais e de cartazes, teria procurado adaptar as estratégias comunicativas da poesia aos novos tempos, à diferença de Baudelaire, por exemplo, visto como formalmente conservador. 
meios de comunicação como matrizes das experiências mallarmeanas, representativas de uma nova concepção de civilização, marcada pela "simultaneidade e (pela) interpenetração" (CAMPOS, 1997, p. 255). Ao apontar o fenômeno metalinguístico, Haroldo associa o "ato de poetar (com) a crise ou a possibilidade mesma do poema, tal como se o poeta estivesse assumindo em seu ofício o dilema hegeliano e marxiano, perguntando-se sobre a morte ou o devir da poesia" (CAMPOS, 1997, p. 255); a conclusão é que se trata de uma poesia que tematiza seu fazer, e vai ganhando com isso mais especificidade e emancipação.

Na economia do raciocínio desse texto de 1968, ainda em clima de vanguarda, a percepção genérica da "consciência da crise da linguagem e da própria crise da poesia ou da arte" é o pano de fundo para um desenvolvimento claro da ideia de inovação, de especificidade, de emancipação da poesia. Já as consequências tiradas pelo ensaio de 1984, retomando os termos do de 1968, são outras; a ênfase é outra:

\footnotetext{
Tome-se, então, o poema-constelação de Mallarmé como o ponto arquimédico, a grande síntese (ainda que clausulada por um peut-être) daquela poética "universal progressiva” do Romantismo: como o poema que teria conseguido enfrentar o problema da crise ou da impossibilidade da epopeia na Era "Química”, vale dizer, "cindida”, da Modernidade (já assim concebida F. Schlegel), e resolver o impasse em favor da poesia, pelo anúncio de uma nova forma de arte poética, e não, como supostamente se faria necessário, através de uma nova épica de base prosística, o romance, "a moderna epopeia burguesa", o gênero por excelência do mundo irreconciliado e abandonado pelos deuses, tal como, ao invés, prefere pensar o jovem Lukács na esteira de Hegel. (CAMPOS, 1997, p. 256)
}

O que, no ensaio de 1968, era uma reflexão sobre a transformação da comunicação e dos meios técnicos que permitem à poesia interagir com o presente, torna-se agora, mais decisivamente, necessidade de superação do "impasse" histórico da crise - o modo como a obra pode resolvê-lo "em favor da poesia". Não são leituras incompatíveis, evidentemente. Mas minha hipótese é a de que o deslocamento do elemento enfatizado na leitura de Mallarmé permite avaliar as transformações da própria obra de Haroldo de Campos, na passagem que ocorre - para usar os termos habituais - entre a fase concretista e a fase pós-utópica. Muito mais do que a superação das velhas antinomias e a neutralização da utopia, o que vemos em Haroldo é a retomada e o deslocamento da arqué vanguardista: ou seja, a necessidade de refundação daquilo que vai mal; a percepção de que as coisas vão mal (tal como se apresentam do ponto de vista do desejo transformador) e de que, só dando conta disso, desse fundo (ainda que sem ter à vista um fundo), seria possível re-fundá-las. 
Na formulação mais ampla, passamos da crise do verso ao impasse do épico, palavra que coloca em jogo a efetividade da força poética de fundação, que eu aproximaria a seu caráter "cerimonial" (para usar o termo de Mallarmé). Dizendo de outra forma, passamos de uma ênfase nas transformações do verso para uma ênfase na profundidade da crise. Em Haroldo, essas duas ênfases não se colocam em relação de oposição, mas servem como extremos de uma alavanca com a qual, a meu ver, o poeta-crítico promoveu, ao longo do tempo, seus próprios deslocamentos - deslocando primeiramente a resistência da crise com a força de apoio do verso e, em seguida, deslocando a resistência do verso com a força de apoio da crise.

Se, passando a sua produção poética, abordarmos especificamente a última fase da poesia de Haroldo, perceberemos que a declaração do fim da utopia convive, não exatamente com uma liberação das possibilidades criativas, mas com a multiplicação dos signos que remetem à questão cerimonial da poesia. Como se Haroldo buscasse esse novo ponto de apoio, sinalizando uma virada tanto na teoria quanto na poesia.

Lembremos que, juntamente com a conclusão do longo projeto de Galáxias (publicadas em 1984, mas iniciadas na década de 1960), o poeta revê os termos da militância anterior, promovendo um retorno ao verso livre e aprofundando o caráter pessoal das referências poéticas. Em $A$ educação dos cinco sentidos, de 1985, Haroldo não deixa de sinalizar essa alteração de rumo e de época, já na contracapa, à qual me referi. Mas o faz também remetendo à necessidade de manter viva a enteléquia no "arco voltaico dos cinquent'anos” (CAMPOS, 1985, p. 29). A poesia, eletrizada, é chamada de "fogo", e não de forma, ou gestalt. Ainda que continue trazendo traços característicos da escrita de Haroldo, como a preciosidade vocabular e as frases extremamente seccionadas, ou "trançadas", segundo seu próprio termo, o livro faz também algumas declarações de passagem. Análogo ao "Póstudo", de Augusto de Campos, por exemplo, o curto poema "Minima Moralia" poderia ser uma delas:

já fiz de tudo com as palavras agora eu quero fazer de nada

(CAMPOS, 1985, p. 25)

Texto talvez o mais leminskiano de Haroldo, o poema joga com a ideia de esvaziamento dentro da qual, numa sintaxe mallarmeana, o nada assume a importância. 
A partir daí, alguns temas ou traços já presentes na obra anterior passam a ganhar importância organizadora. O topos da viagem, por exemplo, que já era decisivo em Galáxias, desloca-se e se aprofunda, numa espécie de aventura global, na qual o poeta se mostra como visitante de lugares e culturas. Sua passagem por elas, ao contrário do turismo que Deguy (2007) chama de "cultural", é uma tentativa de assumir as marcas da passagem, de constituir uma poética do turismo. Em Crisantempo (1998), por exemplo, temos seções de poemas escritas no Japão, nos EUA, em Israel, em Tenerife. A ambição planetária desse livro tem paralelo com a ambição constelar de Galáxias, mas enfatiza mais especificamente a pluralidade das aproximações, em detrimento de uma ideia de síntese experimental. Não por acaso, Odisseu, o velho viajante, é uma das figuras desse livro.

Outro tema importante na poesia de Haroldo dessa época é justamente o do heroísmo do poeta, ou o do heroísmo mítico associado à poesia. As referências à epopeia são decisivas. Como sabemos, o poeta se dedicou, no final de sua vida, à tradução de textos de Homero e de outros autores da antiguidade. Esse heroísmo é representado, ainda, por outros grandes mitos, como Fausto e Prometeu, ou ainda por nomes associados à grandiosidade literária da tradição (como Dante, Goethe, Hölderlin), tratados como referências ou modelos para a situação presente, sem desconsiderar, evidentemente, o efeito de ironia que aí vai. A simulação da terza rima, em A máquina do mundo repensada (2000), é apenas o aspecto mais visível dessa tentativa de alinhar-se à húbris dos grandes desafios milenares personificados pela poesia; são ali evocados Dante, Camões, Drummond, entre outros, colocados em paralelo com o desenvolvimento da física moderna e com suas diversas cosmogonias ${ }^{4}$.

Se voltarmos a Crisantempo, veremos que a própria iconografia do livro aponta para o universo clássico, ao qual também se associa (ainda que menos exemplarmente do que n'A máquina do mundo repensada) o mítico e o místico da ciência contemporânea. Traduções da antiguidade clássica greco-romana são inseridas como seções do livro, aspirando serem lidas como parte da obra de seu autor, o qual, segundo o livro, uma "outra escala [...] rege". A escala em questão é a da grandeza, a dos grandes desafios, a das grandes épocas, a dos grandes poetas. Essa húbris haroldiana é traduzida de modo exemplar no texto introdutório do editor e amigo Jacó Ginzburg, que apresenta o poeta a “desdobrar a

$4 \mathrm{O}$ poeta assume explicitamente esses grandes desafios ao incluir-se na nota bibliográfica que a eles remete, ao final do volume. 
sua maturidade poética", comparando-o a um "odisseu das línguas e das linguagens, [que] percorre um vasto mar de inspirações e transcriações". Na esteira do pós-utópico, dessa "poética de escombros", estaria a tarefa de "transverter Babel no ícone de uma reconquistada interlocução universal" (apud CAMPOS, 1998).

Dando crédito ao que diz Ginzburg, a ambição não é pequena e seu contexto assumido é um mar de escombros pelo qual o temerário Odisseu circula. Com efeito, creio que esse fim do mundo é algo mais do que um tema qualquer da fase pós-utópica de Haroldo. As imagens da crise, da impotência, do fim se associam às mitologias da ciência contemporânea pelas quais o viajante circula, a fim de compor sua visão parabólica com ambição planetária. O velho poeta já viu tudo ("meninos eu vi”) e nos relata: "Meninos eu vi" é uma expressão repetida por um poema em que Haroldo associa o esquema místico da visão à honra de já ter visto muita coisa e ombreado os grandes. A nave na velhice vai sem rumo, sem dados ou acaso, na direção do "fim da linha", que é também o "fim do mundo" (CAMPOS, 1998, p. 47). E pedidos mais comezinhos de paz na velhice, em especial para que os jovens poetas não lhe enviem manuscritos, não chegam a quebrar a solenidade cerimonial da situação. A "música planetária" dos novos tempos leva à interrogação: "placentária / rústica / musa quem te ouve?". O poema é escrito em "língua morta" (CAMPOS, 1998, p. 39).

Creio que a imagem que congrega, em Haroldo, todos esses elementos (da viagem, do heroísmo e da relação com o fim) é a do épico Odisseu, o astucioso que é também o ousado, o soberbo, exemplo máximo da húbris. Na possibilidade do heroísmo de Odisseu está depositada a capacidade fundadora da poesia ou, em todo caso, sua função cerimonial. Um dos poemas-chave de Haroldo, nesse sentido, é "Finismundo: a última viagem" (CAMPOS, 1998, p. 53-59), poema em que o "último Odisseu" é uma figura da condição do poeta, diante da nova viagem:

\section{I.}

Último

Odisseu multi-

ardiloso - no extremo

Avernotenso limite - re-

Propõe a viagem.

Trata-se de uma volta de Haroldo ao poema relativamente longo, de sopro épico, que teria plena realização em A máquina do mundo repensada. O poema retoma a questão tradicional da morte de Odisseu, não contada 
pela Odisseia, mas apenas referida, graças à profecia de Tirésias ("thánatos eks halos", "morte que provém do mar salino", na tradução de Haroldo). O tema da morte de Odisseu reaparece, de diferentes formas, em Dante, em Tennyson, em Kazantzakis. Como em Tennyson e Kazantzakis, que chegou a escrever uma "continuação" da Odisseia, muito próxima da métrica e da retórica homérica, Haroldo aborda o mítico silêncio relacionado à morte do herói, retomando-o a partir da audácia de reiniciar a viagem.

Na primeira parte do poema, rechaçando o regaço de Penélope, o Odisseu de Haroldo lança sua quilha às ondas rumo ao "não-mapeado / Finismundo", rumo ao que está além do limite, "ali / onde começa a infranqueada / fronteira do extracéu”. Por conspiração dos deuses, a nave naufraga e sobram apenas as rasuras das águas. O naufrágio de Um lance de dados pode assim encontrar sucedâneo no lugar mítico do naufrágio de Odisseu.

A segunda parte do poema, entretanto, acrescenta um problema. Passamos do tempo verbal do passado e de um tom mais pomposo para um tempo verbal presente com tom mais coloquial. Agora, Odisseu é um "Urbano Ulisses" - designação que não deixa de remeter ao Ulisses, de Joyce, ou, em última instância, à situação degradada do heroísmo, um heroísmo "sobrevivido ao mito". Pode-se, então, perguntar se a segunda parte não permite reler a primeira como uma espécie de heroísmo historicamente revoluto. Odisseu é aquele que "perdeu os companheiros", como diz o poema: o passado concluído poderia ser visto como o fim do coletivismo vanguardista, por alusão ao concretismo. A húbris astuciosa, sobrevivendo ao mito do "acaso computadorizado", já agora se pergunta se não está diante de seu "epitáfio".

\section{Não há. Vigiam-te os semáforos.}

Périplo?

E as sereias tornaram-se "sirenes". Como se o fim da vanguarda, correspondendo à capitulação da húbris (e recusando ao mesmo tempo a consolação da "pompa fúnebre", de alimentar-se da própria glória), instalasse uma poesia-epitáfio, uma poesia do fim do heroísmo poético.

Uma tensão se instaura, então, entre as duas instâncias do poema, uma mais abertamente exposta ao campo do heroísmo, outra lhe recusando a possibilidade. Pergunto-me se é suficiente interpretar a diferença como efeito de uma sucessão histórica, comentada pelo poema. Mesmo que assim fosse, seria preciso reformular a questão, reinstalando-a na perspectiva da retomada do heroísmo trágico ou irônico como fato da obra de Haroldo de Campos. A visão do paraíso, transformada em "postal 
do Éden", é o que "contenta" (segundo a palavra do poema) o poeta e seu "hipocondríaco crítico / leitor". A época de pós-vanguarda é uma época em que o fim da vanguarda se confunde com as imagens do fim da poesia - na qual a falta de efetividade da poesia faz da húbris conquistadora um resto com o qual, então, supostamente nos contentamos. Se, como diz o poeta, na explicação que faz do poema em nota, a segunda parte é uma "paráfrase irônica (da primeira), projetando (o naufrágio de Mallarmé) no cenário contemporâneo" (CAMPOS, 1998, p. 353), é-nos permitido também ver aí, nesse pathos da crise, o modo como a obra de Haroldo se permite ousar, reincidir, sulcar mais uma vez o tempo presente.

O efeito gangorra da alavanca haroldiana é voluntarioso, prolífico, vertiginoso. O Haroldo das pragas e do fim (que se manifestam exemplarmente no livro póstumo Entremilênios, de 2009) é também aquele para quem o desejo do épico, de comunidade, o desejo de mobilizar a crise a seu favor é o mais evidente. Definido pela viúva Carmen de P. Arruda Campos (que reuniu os poemas de Entremilênios) como obra de um Odisseu que "tinha pressa, muita pressa", o livro se assemelha a um testamento poético, que retoma e organiza as vertentes da última fase de sua poesia: as viagens, o épico, a tradução, os acontecimentos políticos, o diálogo com as artes plásticas. A musa "não se medusa: / contra o caos / faz música" (CAMPOS, 2009, p. 65). O tom é de um "sagrado / furor", que confirma a citação de Benjamin, segundo a qual o "desespero" é o motor da "esperança"; o portal no novo milênio (como diz o poema chamado "20oo") é sustentado por duas pilastras: a do "princípio-esperança" e a do "moiradesespero" (CAMPOS, 2009, p. 59). O patriarca, com o gládio em punho, identificando-se com o sábio bíblico do Eclesiastes, fere o contemporâneo com sua húbris, como um anjo-esperança, fazendo de si mesmo o retrato daquele-que-disse, ou seja, que legislou performativamente ("fa- / lei") velho mestre no comando do navio da poesia.

Se a ambição parece excessiva, creio que ela se sustenta em um dispositivo que ganha o primeiro plano na poesia pós-utópica de Haroldo: a autorreferência do autor enquanto figura pública. Esse dispositivo é o modo que a obra de Haroldo de Campos encontra para se sustentar diante do paradoxo da crise, que faz de cada poeta pós-utópico, ao mesmo tempo, o último Odisseu e um impossível Odisseu. Se Haroldo valoriza o "poeta do poeta”, aquele para quem a própria poesia é sua matéria principal, não é sem se colocar na situação do poeta de si próprio, poeta de seu nome próprio, de sua efígie pública. Algo como um tom memorialístico reforça a exposição de momentos da história pregressa, compondo um mosaico de remissões no qual reconhecemos não apenas viagens, lugares e situações pessoais, mas também encontros e descrições de intelectuais, cientistas e 
artistas renomados com quem o poeta teve contato. Chamado a escrever regularmente sobre as grandes questões do contemporâneo, inclusive políticas (a exemplo da questão dos sem-terra ou das candidaturas do PT à presidência), Haroldo escreve textos em verso e se coloca, igualmente, como personagem público que registra sua participação e seus pontos de vista. Esse vínculo entre o poema e o poeta é reforçado, ainda, pelas notas de contextualização (pouco comuns em livros de poemas) que povoam A educação dos cinco sentidos e Crisantempo, mas que não deixam de aparecer também em $A$ máquina do mundo repensada, na forma de uma bibliografia temática, no final do livro.

A estratégia (mesmo quando transforma o poema em recado para desafetos ou para os fãs, ou inclui biografia e fotos pessoais no final do volume de versos) não pode ser julgada apenas do ponto de vista moralista, como fenômeno narcísico, nem tampouco, por mera e simétrica inversão, como prerrogativa conquistada e merecida pelo velho artista de renome. Caberia, em primeiro plano, explicar suas raízes e definir sua função.

Esse é o passo mais difícil, mas também o mais decisivo. Creio que poderíamos entender a húbris ou a soberba haroldiana dessa última fase como uma espécie de suplemento daquilo que se esvazia com a "pluralização das poéticas possíveis" reivindicada pelo ensaio de 1984. A autoridade e, portanto, a legitimidade histórica daquilo que é excluído como elemento datado, descartado por anacronismo, volta como traço de estilo significativo. Entregue à diversidade de opções possíveis e à necessidade de estabelecer um lugar dentro de sua ideia de "agoridade", a poesia precisa de novos pontos de referência, de novos pontos arquimédicos, novas audácias que a legitimem.

Sea última poesia de Haroldo as reencontra na antiguidade, na epopeia da velhice, da volta de Odisseu ao lar - rico de seus despojos de guerra, na perspectiva da reapropriação de seus bens, esposa, empregados, animais -, seu Odisseu é o Odisseu que parte, que reinicia a viagem (o que já era o caso no livro-viagem Galáxias); porém, mais especificamente, tratase agora do Odisseu da morte não narrada, o Ulisses do contemporâneo rebaixado, que relê Mallarmé a partir do naufrágio e da crise. Odisseu se identifica, a partir dali, com o mestre ancião do poema de Mallarmé, a personificação do próprio verso, hesitando sobre o navio entregue à diversidade, ou à probabilidade, que lhe advém de seu naufrágio.

Ao colocar-se nessa posição, autorizado pelas cãs e pela narrativa das realizações pregressas, Haroldo assume uma atitude historicamente ativa. O poeta sente os cataclismos dos quais é feita a contemporaneidade e com eles pretende novamente singrá-la. Colocar-se na posição do último poeta, do "último homem", ou seja, daquele que sofre com a fragilidade da 
relação com o fim, é seu pacto e sua estratégia. Ao mesmo tempo em que essa posição lhe permite sustentar uma visão crítica do contemporâneo, coloca-o na situação ambivalente ou incerta de não ter a quem legar ("legs en la désaparition"; "legado na desaparição", diz Um lance de dados; MALLARMÉ, 1998) o testemunho cabal de seu próprio fim. A crise, aqui, é a figura usada pela poesia para metamorfosear-se em si mesma, ou seja, mortal, ou ainda, humana: "naufrage cela direct de l'homme / sans nef" ("naufrágio isso direto do homem / sem nau"; MALLARMÉ, 1998).

Desse conflito, resta em Haroldo, em substituição à militância, na fase pós-utópica de sua poesia, um tom de profecia, de "sagrado furor", relacionados ao desespero e ao apocalipse. Não se trata, segundo entendo, de ver aí um abandono da poesia, após ter declarado o fim da ideologia de vanguarda, mas um convite a retrilhar o moderno para além da leitura que as vanguardas nos ofereceram dele, ou seja, daquilo que nos habituamos a entender como "poesia". Talvez por isso Haroldo de Campos seja mais mallarmeano do que poderia admitir.

\section{REFERÊNCIAS BIBLIOGRÁFICAS}

CAMPOS, Haroldo. A educação dos cinco sentidos. São Paulo: Perspectiva, 1985. . O arco-íris branco. Rio de Janeiro: Imago, 1997.

. Crisantempo. São Paulo: Perspectiva, 1998.

. A máquina do mundo repensada. São Paulo: Ateliê, 2000.

. Entremilênios. São Paulo: Perspectiva, 2009.

DEGUY, Michel. Réouverture après travaux. Paris: Galilée, 2007.

. Reabertura após obras. Trad. Marcos Siscar e Paula Glenadel. Campinas: Editora da Unicamp, 2010.

HOLLANDA, Heloísa Buarque de. Esses poetas: uma antologia dos anos 9o. Rio de Janeiro: Aeroplano, 1998.

MALLARMÉ, Stéphane. Oeuvres complètes, t.1. Org. Bertrand Marchal. Paris: Gallimard, 1998. 